\title{
A Study on Immunosuppressant Induced Dyslipidemia and Associated Chronic Graft Rejection in Renal Transplant Recipients
}

\author{
P. Samuel Gideon George*, K. Dhivya \\ Department of Pharmacy Practice and Pharm D, School of Pharmaceutical Sciences, Vels University (VISTAS), Pallavaram, Chennai -600117, India.
}

\begin{tabular}{|c|c|}
\hline ARTICLE INFO & ABSTRACT \\
\hline Article history: & Dyslipidemia is a common complication of renal transplantation referred to as new onset dyslipidemia. Immune \\
\hline Received on: 09/12/2015 & suppressants, in particular cyclosporine, the calcineurin inhibitor and others are known to cause dyslipidemia \\
\hline Revised on: 22/01/2016 & through non-competitive inhibition of sterol 27-dehydroxylase (CYP27A1). On the other hand, dyslipidemia has \\
\hline Accepted on: 08/02/2016 & been found to be associated with higher graft rejection due to decrease in immune suppressant activity and direct \\
\hline Available online: $30 / 04 / 2016$ & graft destruction. Hence the study was designed to analyze the effect of dyslipidemia on chronic allograft \\
\hline Key $w$ & $\begin{array}{l}\text { rejection. Clinical and biochemistry reports of } 142 \text { renal transplant recipients were collected in designed case } \\
\text { report forms. All statistical analysis was carried out using International Business Machine (IBM) Statistical }\end{array}$ \\
\hline $\begin{array}{l}\text { Renal transplant, } \\
\text { immunosuppressant, } \\
\text { metabolic syndrome, } \\
\text { dyslipidemia, graft rejection. }\end{array}$ & $\begin{array}{l}\text { Package for Social Sciences (SPSS) } 17.0 \text {. Immunosuppressive therapy, comorbid diabetes and hypertension, age } \\
\text { and serum creatinine were found to be the common predictors of dyslipidemia whereas as dyslipidemia, age and } \\
\text { gender were found to be predictors of graft destruction and loss }(\mathrm{P}>0.05) \text {. Incidence of graft loss was found } \\
\text { higher in dyslipidemic patients }(\mathrm{P}<0.05) \text {. Dyslipidemia is associated with higher incidence of graft loss and } \\
\text { hence renal transplant recipients should be effectively managed with dose intense statin therapy or other safer } \\
\text { immunosuppressants. This could increase graft survival rates. }\end{array}$ \\
\hline
\end{tabular}

\section{INTRODUCTION}

Renal transplantation is the surgical placement and vascular integration of a human kidney from a living or cadaveric donor into a patient who has end stage renal disease (ESRD). It is the only treatment modality that restores reasonable renal function in ESRD patients (Wallace, 1998). Though, renal function is restored to some extent, renal transplantation possesses various short term and chronic complications, the most important being cardiovascular and post-transplant metabolic syndrome (PTMS) (Stephanie et al., 2009; Oruc et al., 2013). Cardiovascular complications remain the major cause of morbidity and mortality in renal transplant recipients (Kasiske et al., 1996). These long term complications are not direct effects of grafting but are caused due to the dose intense immunesuppressant and long term steroid therapy.

The US National cholesterol education program - Adult treatment panel III defines metabolic syndrome as the presence

\footnotetext{
* Corresponding Author

Email:psgsamuel@gmail.com
}

of dyslipidemia, obesity, glucose intolerance and hypertension. Metabolic syndrome is characterized by presence of several metabolic anomalies associated with increased risk of cardiovascular mortality (Scott et al., 2001; Shadab and Richard, 2012). Dyslipidemia is one of the common PTMS complications and is referred as new onset dyslipidemia after transplantation. It is characterized by an increase in total cholesterol (TC), low density lipoprotein (LDL-C), very low density lipoprotein (VLDL-C) and triglycerides (TGL) and/or decrease in high density lipoprotein levels (HDL-C) (Deleuze et al., 2006). Most of the immunosuppressants, in particular, cyclosporine used in renal transplant recipients to prevent immune sensitization and graft rejection alter serum lipid levels (Sasa and Gerhard, 2012).

Being metabolized by the cytochrome P450 pathway, cyclosporine non competitively inhibits sterol 27-dehydroxylase (CYP27A1) and therefore decreases the production of 27hydroxycholesterol which in turn is a potent inhibitor of 3-hydroxy- 3- methylglutaryl coenzyme A (HMG-CoA), the rate limiting step of cholesterol biosynthesis. In addition to CYP27A1 inhibition, cyclosporine also inhibits lipoprotein lipase and thereby 
increases serum triglyceride levels (Ann et al., 2007 and Tory et al., 2008). Similar to calcineurin inhibitors, patients treated with mammalian target of rapamycin inhibitors (mTOR) such as sirolimus also display impaired lipid metabolism. However, dyslipidemia associated with sirolimus is not completely due to CYP27A1 inhibition as with cyclosporine (Morrisett et al., 2003).

Sirolimus, in addition to CYP27A1 inhibition also decreases LDL-C clearance by inhibiting the transcription of LDL receptor gene in hepatic cells (Ma et al., 2007). Various studies have shown dyslipidemia to be associated with graft rejection. However, many studies have not examined the effect of immunosuppressant induced dyslipidemia on graft rejection. Hyperlipidemia can affect chronic allograft function indirectly by its effects on vessels and directly by its specific renal destructive effects.

Mechanisms of hyperlipidemia induced nephrotoxicity include the following: glomerulosclerosis and chronic interstitial nephritis caused by oxidant stress put forth by generation of reactive oxygen species (Fuiano et al., 2005) and progressive renal damage provoked by monocyte infiltration and mesangial proliferation through increased production of growth promoting cytokines (Keane et al., 1993). Another interesting mechanism behind, dyslipidemia associated graft rejection is decrease in immunosuppressive activity of cyclosporine with increase in serum lipids which ultimately may lead to immune sensitization.

Dyslipidemia decreases the availability of intracellular cyclosporine concentration available to inhibit the immune activation process and thereby contributes to chronic allograft loss (Pozzetto et al., 2008). Thus dyslipidemia induced by immunosuppressants tends to decrease the effect of immunosuppressant by decreasing its availability and leading to graft loss.

\section{MATERIALS AND METHODS}

This retrospective observational study was carried out in the nephrology department of a multispecialty hospital for a period of 2 months from January 2015-March 2015. Consent from the hospital authorities and nephrologists were obtained before accessing patient medical records. The study protocol was approved by the institutional ethics committee of Vels University. Clinical and biochemistry reports of 142 renal transplant recipients who visited the hospital in the past one year for any of the following reason was recorded: hemodialysis, routine checkup as instructed by the nephrologist, transplant kidney biopsy and for other comorbidities. Clinical data was recorded from the patient case sheets stored in medical records whereas biochemical parameters were recorded from the laboratory database. A case report form was designed for recording clinical and biochemistry data of renal transplant recipients as per study requirements.

\section{Inclusion Criterion}

The study included chronic kidney disease or ESRD patients of both gender who have undergone unilateral or bilateral renal transplantation.

\section{Exclusion Criterion}

Chronic kidney disease or ESRD patients on renal replacement therapies other than transplantation were excluded from the study. Patient case sheets with incomplete clinical data were not considered for inclusion in the study. For graft rejection dependency analysis, acute rejection episodes were excluded from the study.

\section{Statistical Analysis}

Comparison between two groups was analyzed by means of student $t$ test to determine the presence or absence of statistically significant difference. Contingency and relationship was analyzed using Fishers's exact test whereas incidence rate between two set of variables was analyzed by odds ratio and relative risk quantification. Wherever computed, a $\mathrm{P}$ value of less than 0.05 was considered significant, since the confidence interval was maintained at $95 \%$.

Predictors of dyslipidemia development and graft rejection were determined by multiple linear regression analysis. All statistical analyses were performed using IBM SPSS 17 statistics package and Graphpad Prism 6.0.

\section{RESULTS}

The study population for the retrospective analysis included Chronic Kidney Disease patients (CKD) who had undergone unilateral or bilateral renal transplantation, receiving immunosuppressant and are on regular visit to the hospital for either of the following reasons: hemodialysis, routine checkup at regular intervals as instructed by the nephrologist, biopsy of transplanted kidney and for any other comorbidity. Age wise distribution of patients considered for the study is shown in Table 1. $67.7 \%$ patients were males whereas $32.3 \%$ patients were females.

Table 1: Age Wise Distribution of Renal Transplant Recipients.

\begin{tabular}{ccccccc}
\hline $\begin{array}{c}\text { Age } \\
\text { (Years) }\end{array}$ & $\begin{array}{c}\text { No. of } \\
\text { patients } \\
(\mathbf{n = 1 4 2})\end{array}$ & $\begin{array}{c}\text { Percentage } \\
(\boldsymbol{\%})\end{array}$ & Mean & SD & $\begin{array}{c}\text { Age } \\
\text { Quartiles }\end{array}$ & $\begin{array}{c}\text { Median } \\
\text { age }\end{array}$ \\
\hline $11-20$ & 9 & 6.34 & 16.6 & 2.21 & $13-20$ & 17 \\
$21-30$ & 12 & 8.45 & 25.1 & 0.79 & $24-27$ & 25 \\
$31-40$ & 27 & 19.01 & 35.6 & 3.3 & $31-40$ & 36 \\
$41-50$ & 28 & 19.72 & 46.3 & 2.62 & $41-50$ & 47 \\
$51-60$ & 46 & 32.39 & 54.8 & 2.55 & $51-60$ & 54 \\
$61-70$ & 16 & 11.27 & 62.4 & 1.36 & $61-66$ & 62 \\
$71-80$ & 4 & 2.82 & 74.5 & 0.86 & $73-75$ & 75 \\
\hline
\end{tabular}

Mean age $=46.01 \pm 14.02$, Median age $=49$.

The incidence of single and combined immunosuppressant usage between genders was found to be almost similar with no statistically significant difference $(\mathrm{P}$ value $=0.1671$, odds ratio $=0.2148$ ) and is shown in Table 2. 
Table 2: Distribution of Patients based on Immunosuppressive Regimen.

\begin{tabular}{|c|c|c|c|c|c|}
\hline \multirow[b]{2}{*}{$\begin{array}{c}\text { Immunosuppressive } \\
\text { Regimen }\end{array}$} & \multicolumn{3}{|c|}{ No.of Patients } & \multirow{2}{*}{ 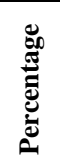 } & \multirow[b]{2}{*}{$\begin{array}{l}\text { Statistical } \\
\text { Parameters }\end{array}$} \\
\hline & $\sum_{\bar{\pi}}^{\frac{0}{\pi}}$ & 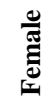 & $\stackrel{5 \pi}{\frac{\pi}{6}}$ & & \\
\hline $\begin{array}{l}\text { Mono-Immunosuppressive } \\
\text { therapy }\end{array}$ & 87 & 45 & 132 & & $P$ value $=0.1671$ \\
\hline $\begin{array}{l}\text { Combined Immunosuppress } \\
\text { therapy }\end{array}$ & 9 & 1 & 10 & & Odds ratio $=0.2148$ \\
\hline
\end{tabular}

The incidence of single and combined immunosuppressant usage between genders was found to be almost similar with no statistically significant difference $(\mathrm{P}$ value $=0.1671$, odds ratio $=0.2148)$. The patients received concomitant steroid therapy with prednisolone $(80.2 \%)$, methyl prednisolone $(11.9 \%)$ and hydrocortisone $(1.4 \%) .6 .3 \%$ patients did not receive concomitant steroid therapy.

Out of the 142 patients studied, 109 (76.7\%) patients received immunosuppressive antimetabolite therapy with mycophenolatemofetil whereas $33(23.2 \%)$ patients did not.

Distribution of patients on the basis of immunosuppressants received is as shown in Table 3.

Table 3: Distribution of Patients Based on the Immunosuppressant .

\begin{tabular}{cccccc}
\hline $\begin{array}{c}\text { S. } \\
\text { No }\end{array}$ & $\begin{array}{c}\text { Immunosup } \\
\text { pressant }\end{array}$ & $\begin{array}{c}\text { No.of } \\
\text { Patients }\end{array}$ & Percentage & $\begin{array}{c}\text { Median } \\
\text { Dose }\end{array}$ & $\begin{array}{c}\text { Daily Dose } \\
\text { Quartile }\end{array}$ \\
\hline 1 & Cyclosporine & 87 & 61.27 & $100 \mathrm{mg}$ & $25-300 \mathrm{mg}$ \\
2 & Tacrolimus & 48 & 33.80 & $2.5 \mathrm{mg}$ & $0.5-20 \mathrm{mg}$ \\
3 & Sirolimus & 8 & 5.63 & $1 \mathrm{mg}$ & $0.5-1.5 \mathrm{mg}$ \\
4 & Azathiorpine & 2 & 1.41 & $62.5 \mathrm{mg}$ & $50-75 \mathrm{mg}$ \\
5 & Rituximab & 6 & 4.23 & $500 \mathrm{mg}$ & $100-500 \mathrm{mg}$ \\
\hline
\end{tabular}

The glomerular filtration rate is an endogenous marker of renal function that requires 24 hours urine collection. However, GFR can theoretically be estimated using the modification of diet in renal disease (MDRD) formula from serum creatinine and age of the patient. Renal transplant recipients in the study have been segregated into different GFR quartiles as shown in Table 4.
Table 4: Distribution of Patients Based on Estimated Glomerular Filtration Rate.

\begin{tabular}{|c|c|c|c|c|c|}
\hline 悪总范 & 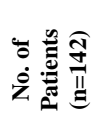 & 总 & 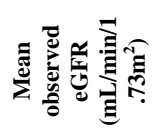 & के & 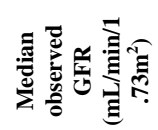 \\
\hline$\leq 15$ & 44 & 30.9 & 10.5 & 2.8 & 10.6 \\
\hline $15-29$ & 42 & 29.5 & 20.7 & 3.7 & 20.3 \\
\hline $30-59$ & 39 & 27.4 & 41.3 & 7.6 & 40.9 \\
\hline $60-89$ & 11 & 7.7 & 70.9 & 6.4 & 72.1 \\
\hline$>90$ & 6 & 4.2 & 104.2 & 13.7 & 100.5 \\
\hline
\end{tabular}

Mean \pm SD GFR $=30.6 \pm 23.9 \mathrm{~mL} / \mathrm{min} / 1.73 \mathrm{~m}^{2}$, Median GFR $=21.59$ $\mathrm{mL} / \mathrm{min} / 1.73 \mathrm{~m}^{2}$

The comorbidities observed in renal transplant recipients taken for the study are shown in Figure 1. Various comorbidities observed can directly be attributed immunosuppressants or posttransplant causes. Due to various sub-types, dyslipidemia is enlisted separately in Table 5. Hypertension was the common comorbidity due to increase in electrolyte retention and altered renal dynamics in transplant recipients. Dyslipidemia can either be increase in Total cholesterol, LDL, VLDL, triglycerides or decrease in serum HDL levels.

Table 5: Patterns of Dyslipidemia observed in the Study Population.

\begin{tabular}{|c|c|c|c|c|}
\hline $\begin{array}{c}\text { S. } \\
\text { No }\end{array}$ & Lipid Parameter & 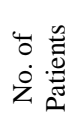 & 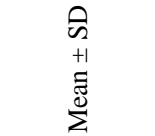 & 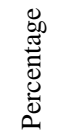 \\
\hline 1 & Total Cholesterol $(<200 \mathrm{mg} / \mathrm{dl})$ & 63 & $219.3 \pm 14.3$ & 44.3 \\
\hline 2 & $\operatorname{LDL}(<130 \mathrm{mg} / \mathrm{dl})$ & 72 & $148.07 \pm 13.7$ & 50.7 \\
\hline 3 & $\operatorname{VLDL}(<30 \mathrm{mg} / \mathrm{dl})$ & 82 & $42.3 \pm 8.4$ & 57.7 \\
\hline 4 & $\mathrm{HDL}(>40 \mathrm{mg} / \mathrm{dl})$ & 83 & $22.5 \pm 9.09$ & 58.4 \\
\hline 5 & Triglycerides $(<150 \mathrm{mg} / \mathrm{dl})$ & 108 & $256.9 \pm 71.2$ & 76 \\
\hline
\end{tabular}

Incidence of dyslipidemia between genders was determined in renal transplant recipients included in the study. The results are graphically represented in Figure 2. Females possess less risk of developing dyslipidemia because of presence of estrogen hormones.

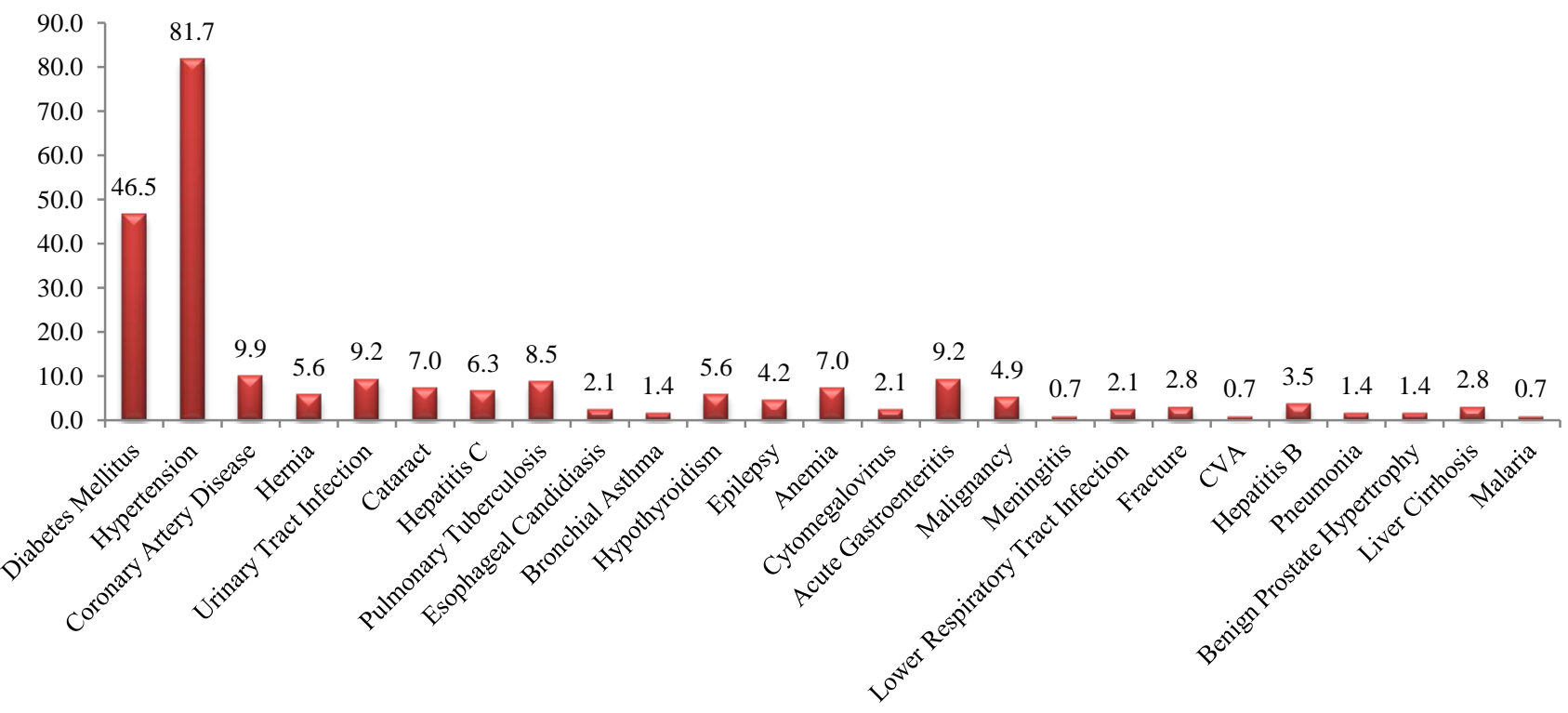

Fig. 1: Distribution based on Comorbidities Observed. 
Steroids possess well established potential to cause posttransplant metabolic syndrome including dyslipidemia. Hence, the incidence of dyslipidemia was compared between patients on steroid and off steroid therapy using Fisher exact tests at 95\% confidence interval and the result is graphically represented in Figure 3 .

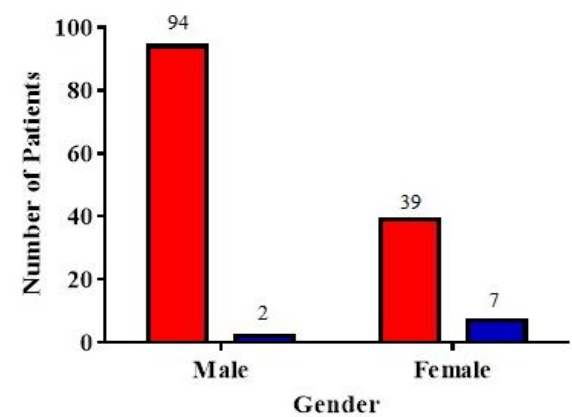

Fig. 2: Incidence of Dyslipidemia between Genders in Renal Transplant Recipient $(\mathrm{P}$ Value $=0.0054$, odds ratio $=8.436$, relative risk $=1.155)$

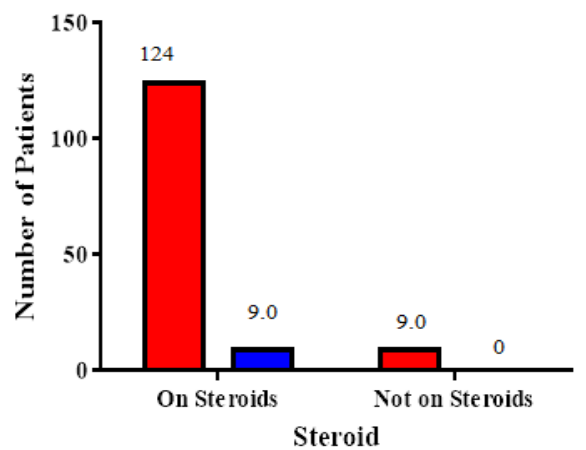

Fig. 3: Incidence of Dyslipidemia between on steroid and off steroid group (P value $>0.05$, Odds Ratio $=0.6896, R R=0.9323$ ).

Stepwise Multiple Linear Regression analysis was done to determine the predictors of dyslipidemia in renal transplant recipients on immunosuppressive therapy. The following independent variables were regressed against every individual lipid parameters which were taken as dependent variables: age, gender, immunosuppressive regimen and its dose, concomitant steroid therapy and steroid dose, systolic and diastolic blood pressures, comorbid diabetes mellitus, serum creatinine, number of post-transplant years and dialysis history. Age, immunosuppressant and steroid dose, blood pressures, serum creatinine and number of post-transplant years were given as continuous numerical predictors whereas gender, regimen, concomitant steroid, comorbid diabetes mellitus and dialysis history were given as categorical predictors. The results of MLR analysis is shown in Table 6 and the predictors of each regression model are listed below the table.

Table 6: Stepwise Multiple Linear Regression to Determine Predictors of Dyslipidemia.

\begin{tabular}{ccccc}
\hline Lipid Parameter & $\mathbf{R}$ & $\begin{array}{c}\text { R } \\
\text { Square }\end{array}$ & $\begin{array}{c}\text { Adjusted R } \\
\text { Square }\end{array}$ & $\begin{array}{c}\text { Std. Error of } \\
\text { the Estimate }\end{array}$ \\
\hline Total Cholesterol & $0.422^{\mathrm{a}}$ & 0.178 & 0.161 & 23.163 \\
LDL-C & $0.452^{\mathrm{b}}$ & 0.205 & 0.181 & 20.6 \\
VLDL-C & $0.328^{\mathrm{c}}$ & 0.107 & 0.095 & 12.65 \\
HDL-C & $0.225^{\mathrm{d}}$ & 0.050 & 0.044 & 14.673 \\
Triglycerides & $0.448^{\mathrm{e}}$ & 0.201 & 0.171 & 77.29 \\
\hline
\end{tabular}

Where the predictors are,

a. Immunosuppressant dose, steroid dose, gender

b. Immunosuppressant dose, Age, Systolic BP, Steroid dose

c. Age, Gender

d. Steroid dose

e. Immunosuppressant dose, DM, Systolic BP, Age, Serum creatinine.

Transplant kidney biopsy reports of patients with abnormal patterns were correlated with their serum lipid profiles. The abnormal patterns of grafts observed in renal transplant recipients are as shown in Table 7.

Incidence of graft disturbances betweendyslipidemic and non-dyslipidemic patients is shown in Table 8. Almost all patients with stable functioning grafts and comorbid dyslipidemia had adequate systemic control of lipids with concomitant statin therapy.

Table 7: Correlation of Serum Lipid Profile with Abnormal Graft Patterns.

\begin{tabular}{|c|c|c|c|c|c|c|}
\hline $\begin{array}{l}\text { S. } \\
\text { No }\end{array}$ & Gender & Age & $\begin{array}{c}\text { Years of } \\
\text { Transplant }\end{array}$ & Immunosuppressive Regimen & DyslipidemicConditions & Biopsy Findings \\
\hline 1. & Male & 59 & 9 & Cyclosporine, Sirolimus, Prednisolone & 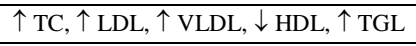 & Chronic Allograft Nephropathy \\
\hline 2. & Male & 47 & 13 & $\begin{array}{l}\text { Tacrolimus, Prednisolone, } \\
\text { Mycophenolate }\end{array}$ & $\uparrow \mathrm{VLDL}, \uparrow \mathrm{TGL}$ & Chronic Allograft Nephropathy \\
\hline 3. & Male & 47 & 11 & Tacrolimus & $\uparrow \mathrm{TGL}$ & Chronic Allograft Nephropathy \\
\hline 4. & Female & 63 & 8 & $\begin{array}{l}\text { Cyclosporine, Prednisolone, } \\
\text { Mycophenolate, Rituximab }\end{array}$ & $\uparrow \mathrm{TC}, \uparrow \mathrm{LDL}, \uparrow \mathrm{VLDL}, \downarrow \mathrm{HDL}, \uparrow \mathrm{TGL}$ & Chronic Allograft Nephropathy \\
\hline 5. & Male & 66 & 3.3 & Cyclosporine & $\uparrow \uparrow \mathrm{TC}, \uparrow \mathrm{VLDL}, \uparrow \mathrm{TGL}$ & Chronic Glomerular Nephritis \\
\hline 6. & Male & 46 & 0.9 & Tacrolimus, Prednisolone & $\downarrow \mathrm{HDL}, \uparrow \mathrm{TGL}$ & Focal Segmental Glomerulosclerosis \\
\hline 7. & Female & 25 & 8 & $\begin{array}{l}\text { Cyclosporine, Prednisolone, } \\
\text { Mycophenolate }\end{array}$ & Normal & $\begin{array}{c}\text { Glomerulopathy, Interstitial Fibrosis, } \\
\text { Tubular Atrophy }\end{array}$ \\
\hline 8. & Female & 39 & 7 & $\begin{array}{l}\text { Cyclosporine, Prednisolone, } \\
\text { Mycophenolate }\end{array}$ & 个 $\uparrow \mathrm{TC}, \uparrow \mathrm{LDL}, \uparrow \mathrm{VLDL}, \downarrow \mathrm{HDL}, \uparrow \mathrm{TGL}$ & $\begin{array}{l}\text { Glomerulosclerosis, Interstitial } \\
\text { Fibrosis, Tubular Atrophy }\end{array}$ \\
\hline 9. & Male & 75 & 14 & Cyclosporine, Mycophenolate & ${ }^{\top} \uparrow \mathrm{TC}, \uparrow \mathrm{LDL}, \uparrow \mathrm{VLDL}, \downarrow \mathrm{HDL}, \uparrow \mathrm{TGL}$ & Glomerulpathy, Graft Pyelonephritis \\
\hline 10. & Female & 38 & 1.2 & $\begin{array}{c}\text { Tacrolimus, Prednisolone, } \\
\text { Mycophenolate }\end{array}$ & $\uparrow \mathrm{VLDL}, \downarrow_{\mathrm{HDL}}, \uparrow \mathrm{TGL}$ & $\begin{array}{l}\text { Glomerulpathy, Tubular Atrophy, } \\
\text { Intersitital Fibrosis }\end{array}$ \\
\hline 11. & Male & 53 & 5 & Cyclosporine, Prednisolone & 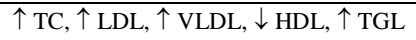 & Interstitial Fibrosis, Tubular Atrophy \\
\hline
\end{tabular}


Table 8: Incidence of Graft Anomalies in Post Renal Transplant Patients.

\begin{tabular}{|c|c|c|c|c|c|}
\hline \multirow[b]{2}{*}{ Gender } & \multicolumn{2}{|c|}{$\begin{array}{c}\text { Dyslipidemic } \\
(\mathrm{n}=122)\end{array}$} & \multicolumn{2}{|c|}{$\begin{array}{l}\text { Notdyslipide } \\
\text { mic }(\mathrm{n}=20)\end{array}$} & \multirow[t]{2}{*}{$\begin{array}{c}\text { Statistical } \\
\text { Parameters }\end{array}$} \\
\hline & 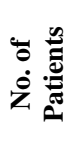 & & 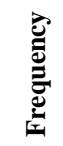 & 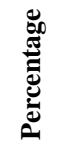 & \\
\hline Graft Destruction & 24 & 16.9 & 2 & 1.4 & \\
\hline $\begin{array}{c}\text { Stable functioning } \\
\text { Graft }\end{array}$ & 98 & 69.01 & 18 & $\begin{array}{c}12.6 \\
7\end{array}$ & $\begin{array}{l}\mathbf{P} \text { value } \\
<0.001 *\end{array}$ \\
\hline
\end{tabular}

Logistic linear regression models were used to determine the effect of dyslipidemia and other predictors of chronic allograft rejection and destruction. The results are given in Table 9and the coefficients of individual components of the built regression model are summarized in Table $\mathbf{1 0 .}$

Table 9: Stepwise Multiple Linear Regression to Determine Predictors of Graft Rejection.

\begin{tabular}{ccccc}
\hline Model & $\mathbf{R}$ & R Square & $\begin{array}{c}\text { Adjusted R } \\
\text { Square }\end{array}$ & $\begin{array}{c}\text { Std. Error of } \\
\text { the Estimate }\end{array}$ \\
\hline 5 & .613 & .376 & .353 & .312 \\
\hline \multicolumn{2}{l}{ Predictors: (Constant), Triglycerides, Total Cholesterol, Age, HDL, Gender } \\
\hline
\end{tabular}

Table 10: Coefficients of Individual Predictors of Allograft Rejection.

\begin{tabular}{cccccc}
\hline \multirow{2}{*}{ Model } & \multicolumn{2}{c}{$\begin{array}{c}\text { Unstandardized } \\
\text { Coefficients }\end{array}$} & $\begin{array}{c}\text { Standardized } \\
\text { Coefficients }\end{array}$ & \multirow{2}{*}{$\mathbf{t}$} & Sig. \\
\cline { 2 - 4 } & $\mathbf{B}$ & $\begin{array}{c}\text { Std. } \\
\text { Error }\end{array}$ & Beta & & \\
\hline (Constant) & -1.234 & .266 & - & -4.643 & .000 \\
Triglycerides & .002 & .000 & .366 & 4.745 & .000 \\
Total & .005 & .001 & .341 & 4.325 & .000 \\
Cholesterol & .005 & & & \\
Age & -.006 & .002 & .231 & 3.271 & .001 \\
HDL & .005 & .002 & .158 & 2.320 & .022 \\
Gender & -.124 & .057 & -.150 & -2.158 & .033 \\
\hline
\end{tabular}

\section{DISCUSSION}

$61.2 \%$ patients received oral cyclosporine, $33.8 \%$ patients received oral tacrolimus, $5.6 \%$ patients received oral sirolimus, and $1.4 \%$ patients received oral azathioprine whereas $4.22 \%$ patients received rituximab intravenous infusion at median doses of $100 \mathrm{mg}, 2.5 \mathrm{mg}, 1 \mathrm{mg}, 62.5 \mathrm{mg}$ and $500 \mathrm{mg}$ respectively. Since calcineurin inhibitors are the most common immunosuppressant of choice and possess well established dyslipidemic potential, the incidence of cyclosporine usage between genders was determined. For this purpose, patients were segregated into cyclosporine and non-cyclosporine receiving group who were sub-segregated on gender basis. Statistically significant difference in incidence of choice for calcineurin inhibitors exists between genders with a relative risk of 0.7395 ( $\mathrm{P}$ value $=0.0499$, odds ratio $=0.4582$ ).

The immunosuppressive treatment given complies with the KDIGO clinical practice guideline for the care ofkidney transplant recipients (Chapman, 2010).
The modified diet in renal disease (MDRD) formula provides a mean for estimating glomerular filtration rate without 24 hour urine collection. The abbreviated MDRD equation is given below:

GFR $\left(\mathrm{mL} / \mathrm{min} / 1.73 \mathrm{~m}^{2}\right)=186 \times(\mathrm{SCr})^{-1.154} \mathrm{x}(\mathrm{Age})^{-0.203} \mathrm{x}$ 0.742 if female $x 1.210$ if African-American (Levey et al., 2000).

Various comorbidities observed can directly be attributed immunosuppressants or post-transplant causes. Cardiovascular complications remain the major cause of morbidity and mortality in renal transplant recipients. The US National cholesterol education program - Adult treatment panel III defines metabolic syndrome as the presence of dyslipidemia, obesity, glucose intolerance and hypertension. Metabolic syndromes such as posttransplant diabetes mellitus (NODAT), dyslipidemia, hypertension etc. were observed in these patients (Scott et al., 2001). Opportunistic infections are more common in renal transplant recipients due to immunocompromization. In our study, the following opportunistic infections were observed: $9.15 \%$ had urinary tract infections, $9.86 \%$ had hepatitis B and C, $8.45 \%$ had pulmonary tuberculosis, $2.11 \%$ had esophageal candidiasis, $2.11 \%$ had cytomegalovirus infection due to extensive mycophenolate usage (Hambach et al., 2002), 2.11\% patients had lower respiratory tract infection, $1.41 \%$ patients had pneumonia whereas $0.70 \%$ had meningeal infection. Other post-transplant metabolic syndromes observed include diabetes mellitus in $46.47 \%$, hypertension $81.69 \%$. 93.6\% patients displayed some form of dyslipidemia out of which $70.6 \%$ were male and $29.3 \%$ were female thus indicating a higher incidence of dyslipidemia in males. Thus, a statistically significant difference occurs between genders in developing post-transplant dyslipidemia coinciding with the fact that chance of developing dyslipidemia in females is less since they are protected by natural estrogen hormones $(\mathrm{P}$ value $=$ 0.0054) (Paranjape, 2005).

Though dyslipidemia was observed in majority of the study population $(93.6 \%)$, not all patients displayed elevations in all form of lipids. Only $44.3 \%$ patients had elevated TC, 50.7\% had elevated LDL-C, 57.7\% patients had elevated VLDL, 58.4\% patients had HDL-C whereas $76 \%$ patients had hypertriglyceridemia. This is not on par with the results of previous studies which report LDL-C to be the major elevated lipid. However, deviations in our study could be attributed to concurrent statin therapy in these patients (Lentine and Brennan, 2004; Lisik et al., 2007).

Steroids can cause diverse metabolic syndromes on chronic administration. However they are used in combination with immunosuppressants to prevent graft rejection (Helaland Chan, 2011). A comparison to assess the incidence of dyslipidemia in patients receiving and not receiving steroids showed no statistically significant difference between the occurrence of dyslipidemia between the two groups at a confidence interval of $95 \%(\mathrm{P}$ value $>0.05$, relative risk $=0.9323)$ suggesting that steroids are not the only risk factor for development of dyslipidemia in renal transplant recipients. 
The dyslipidemic potential of cyclosporine and tacrolimus vary to great extent. Various studies have comparatively assessed the extent of dyslipidemia associated with cyclosporine and tacrolimus and have shown cyclosporine to predominantly cause dyslipidemia than tacrolimus (Ploskerand Foster, 2000 and Henry, 1999). Cyclosporine induced dyslipidemia is due to a direct non-competetive inhibition of sterol 27-dehydroxylase (CYP27A1) and decrease in production of 27hydroxycholesterol which in turn is a potent inhibitor of 3hydroxy-3-methylglutaryl coenzyme A (HMG-CoA), the rate limiting step of cholesterol biosynthesis. In addition to CYP27A1 inhibition, cyclosporine also inhibits lipoprotein lipase and thereby increases serum triglyceride levels (Ann et al., 2007). Similar to calcineurin inhibitors, patients treated with mammalian target of rapamycin inhibitors (mTOR) such as sirolimus also display impaired lipid metabolism. However, dyslipidemia associated with sirolimus is not completely due to CYP27A1 inhibition as with cyclosporine (Morrisett et al., 2003). Sirolimus, in addition to CYP27A1 inhibition also decreases LDL-C clearance by inhibiting the transcription of LDL receptor gene in hepatic cells (Ma et al., 2007).

The mean TC and LDL levels are significantly higher in the cyclosporine group ( $\mathrm{p}$ value $<0.0001$ ) whereas HDL was high in the cyclosporine group. However, low HDL levels are reported in Cyclosporine treated patients. Decrease in HDL levels predisposes the patient to atherogenic risk (Gerry et al., 2001). Elevated HDL levels in our study could be attributed to concomitant steroid usage. No significant difference was found between HDL and VLDL of the two groups ( $p$ value >0.05). Triglycerides was found to be significantly high in the cyclosporine treated group ( $\mathrm{p}$ value $=0.0012$ ).

A stepwise multiple linear regression analysis was carried out to determine the predictors of dyslipidemia in renal transplant recipients. Dose of the immunosuppressant, concomitant steroid therapy were the continuous predictors for hypercholestrolemia whereas gender was the categorical predictor, with males being more prone $\left(r^{2}=0.17\right)$. However, immunosuppressant, concomitant steroid therapy, age and comorbid systolic hypertension were the predictors of LDL cholesterol in the studied population $\left(r^{2}=0.205\right)$.

We analyzed the transplant kidney biopsy reports of patients with abnormal patterns. Out of the 142 patients, $23.9 \%$ patients have undergone biopsy examination of transplanted kidneys. Out of the $23.9 \%$ patients who have undergone biopsy examination of the transplanted kidney, $32.5 \%$ patients were observed to have abnormal patterns of transplanted kidneys or graft abnormality. Presence of graft abnormality was correlated with dyslipidemia and it was observed that out of the $32.5 \%$ patients with chronic graft abnormality, $90.9 \%$ patients had uncontrolled dyslipidemia. Out of the $32.5 \%$ patients, $72.7 \%$ patients were already on statin therapy. Thus it is clearly evident that patients with dyslipidemia yet controlled by statin therapy have lesser chance of developing graft dysfunction or abnormality when compared to those with uncontrolled dyslipidemia.
However, in order to statistically validate these findings by determination of specific predictors of graft rejection and dysfunction, multiple linear regression analysis was carried out with the following covariates: Lipid profile, age, serum creatinine, systolic and diastolic blood pressures, presence of comorbid diabetes mellitus and number of years after transplantation. Thus dyslipidemia causes allograft rejection which may progress to rejection of graft. The patterns of graft destruction observed in our study include glomerulonephropathy, focal glomerulosclerosis, interstitial nephritis, fibrosis and tubular atrophy. Such patterns of destruction have been previously described in various studies (Colvin, 2007). Though clear mechanisms do not exist for the relation between dyslipidemia and graft loss, various studies have demonstrated certain mechanisms with positive correlations. Based on the existing literature, dyslipidemia induced graft direction could be categorized into two types: Direct and Indirect. Direct mechanisms include the non-specific vascular and specific renal effects. Non-specific vascular effects include the narrowing and thickening of interlobular and arcuate arteries ultimately leading to renal ischemia and graft loss. Special renal effects include oxidant stress induced by hyperlipidemia associated enhanced generation of reactive oxygen species (ROS)that leads to glomerulosclerosis and chronic tubulo-interstitial disease, reduction in normal plasma flow through endotherlial dysfunction and also by stimulation of monocyte infiltration (Stephan, 2002).

Indirect mechanism of graft destruction involves the decrease in the availability of intracellular cyclosporine concentration available to inhibit the immune activation process and thereby contributes to chronic allograft loss. Thus dyslipidemia induced by immunosuppressants tends to decrease the effect of immunosuppressant by decreasing its availability and leading to graft loss (Pozzetto et al., 2008). Hence dyslipidemia has to effectively be managed to prevent graft survival rates and reduce the risk of cardiovascular mortality. Out of 142 renal transplant recipients, $33(23.2 \%)$ patients were found to have some form of graft disturbance or rejection. However 7 (4.9\%) patients with acute graft rejections or acute graft destruction were not coded as "rejections" while building logistic regression models for determining predictors of graft destruction in renal transplant recipients. Thus 26 patients $(18.3 \%)$ patients were observed to have chronic allograft disturbance out of which $15(10.5 \%)$ patients had chronic rejections were as $11(7.7 \%)$ had some form of graft anomaly as diagnosed by renal biopsy marking. Chronic allograft rejections or destruction were associated with some form of dyslipidemia in $92.3 \%$ patients whereas it was not in $7.6 \%$ patients. $81.7 \%$ of the patients had stable functioning grafts of which $69 \%$ was associated with dyslipidemia, yet with adequate control through concomitant statin therapy. Logistic linear regression analysis determined hypertriglyceridemia $(\beta=0.366)$, hypercholestrolemia $(\beta=0.341)$, age $(\beta=0.231)$, HDL $(=0.158)$ and Gender $(\beta=-0.150)$. Thus dyslipidemia seems to be a significant predictor of chronic allograft rejection in renal transplant recipients. Hence dyslipidemia has to be effectively 
managed either with dose intense statin therapy or switching to other immunosuppressants with less dyslipidemic potential.

\section{CONCLUSION}

Post-transplant dyslipidemia is a common adverse effect of immunosuppressants usage. The study has analyzed the differential effects of immunosuppressants on serum lipids and Total Cholesterol, LDL-C, HDL, VLDL and Triglycerides and has determined immunosuppressants as a significant predictor of developing dyslipidemia in renal transplant recipients. Cyclosporine was found to possess comparatively higher dyslipidemic potential when compared to tacrolimus; however, tacrolimus itself too possesses dyslipidemic potential. Dyslipidemia in turn was found to be a significant predictor of chronic allograft nephropathy and rejection. The incidence of graft rejections and disturbances observed in dyslipidemic patients was significantly high when compared with non-dyslipidemic patients. Thus, it is clearly evident that chronic immunosuppressive leads to dyslipidemia that causes graft destruction which progresses to graft loss. Thus, dyslipidemia has to be managed effectively through dose intense statin therapy or by switching to other immunosuppressants with lesser dyslipidemic potential to prevent chronic allograft nephropathy and rejections.

\section{ACKNOWLEDGEMENT}

The authors are thankful to the management of Vels University for providing excellent research support and encouragement.

\section{REFERENCES}

Ann G, Luc F, Maamar S, Anne MB, Claude L, Gerard S et al. Compared effect of immunosuppressive drugs cyclosporine $\mathrm{A}$ and rapamycin on cholesterol homeostasis key enzymes CYP27A1 and HMGCoA reductase. Basic Clin Pharmacol Toxicol, 2007; 100:392-97.

Colvin RB. Antibody-mediated renal allograft rejection: diagnosis and pathogenesis. J Am Soc Nephrol, 2007; 18:104656.

Chapman JR. The KDIGO clinical practice guidelines for the care of kidney transplant recipients. Transplant, 2010; 89(6):644-45.

Deleuze S, Garrigue V, Delmas S, Chong G, Swarcz I, Cristol JP et al. New Onset Dyslipidemia after Renal Transplantation: Is there a Difference Between Tacrolimus and Cyclosporine? Transplant Proc, 2006; 38: 2311-13.

Fuiano G, Mancuso D, Indolfi C, Mongiardo A, Sabbatini M, Conte G. Early detection of progressive renal dysfunction in patients with coronary artery disease. Kidney Int, 2005; 68(6):2773-80.

Gerry L, Ronald JH, Peter JB, Hein AK. Cardiovascular Risk Factors in Renal Transplant Patients: Cyclosporin A versus Tacrolimus. J Am Soc Nephrol, 2001; 12: 368-73.

Henry ML. Cyclosporine and tacrolimus (FK506): a comparison of efficacy and safety profiles. Clin Transplant, 1999;13:209-20

Hambach L, Stadler M, Dammann E, Ganser A, Hertenstein B. Increased risk of complicated $\mathrm{CMV}$ infection with the use of mycophenolatemofetil in allogeneic stem cell transplantation. Bone Marrow Transplant, 2002; 29(11):903-06.

Helal I, Chan L. Steroid and calcineurin inhibitor-sparing protocols in kidney transplantation. Transplant Proc, 2011; 43:472-77.
Keane WF, Kasiske BL, Donnell MP, Kim Y. Hypertension, hyperlipidemia and renal damage. Am J Kidney Dis, 1993; 5(2):43-50.

Kasiske BL, Guijarro C, Massy ZA, Wiederkehr MR, Ma JZ. Cardiovascular disease after renal transplantation. J Am Soc Nephrol, 1996; 7: 158-65.

Levey AS, Greene T, Kusek JW, Beck GJ, Group MS.A simplified equation to predict glomerular filtration rate from serum creatinine. J Am Soc Nephrol, 2000;11:A0828

Lentine KL, Brennan DC. Statin use after renal transplantation: a systematic quality review of trial-based evidence. Nephrol Dial Transplant, 2004; 19:2378-86.

Lisik W, Schoenberg L, Lasky RE. Statins benefit outcomes of renal transplant recipients on a sirolimus-cyclosporine regimen. Transplant Proc, 2007; 39:3086-92.

Morrisett JD, Abdel FG, Kahan BD. Sirolimus changes lipid concentrations and lipoprotein metabolism in kidney transplant recipient.Transplant Proc, 2003; 35(3):143-50.

Ma KL, Ruan XZ, Powis SH, Chen Y, Moorhead JF, Varghese Z. Sirolimus modifies cholesterol homeostasis in hepatic cells: a potential molecular mechanism for sirolimus associated dyslipidemia. Transplant, 2007; 84(8):1029-36.

Oruc M, Koseoglu K, Seyahi N, Alagoz S, Trabulus S, Altiparamak MR. Progression of metabolic syndrome in renal transplant recipients. Transplant Proc, 2013; 45: 3273-78.

Plosker GL, Foster RH. Tacrolimus: a further update of its pharmacology and therapeutic use in the management of organ transplantation. Drugs, 2000; 59:323-89.

Paranjape SG, Turankar AV, Wakode SL, Dakhale GN. Estrogen protection against coronary heart disease: are the relevant effects of estrogen mediated through its effects on uterus--such as the induction of menstruation, increased bleeding, and the facilitation of pregnancy? Med Hypotheses, 2005; 65(4):725-27.

Pozzetto U, Citterio F, Fioravanti G, Navarra P, Boccalini F, Castagneto M. Dyslipidemia can reduce the immunosuppressive effects of cyclosporine. TransplImmunol, 2008; 18(4):349-51.

Scott MG, Diane B,Luther TC,Richard SC,Margo AD, Donald $\mathrm{BH}$ et al. Executive summary of the third report of the National Cholesterol Education Program (NCEP) expert panel on detection, evaluation, and treatment and treatment of high blood cholesterol in adults. JAMA J, 2001; 285(19): 2486-97.

Stephan A, Barbari A, Karam A, Kilani H, Kamel G. Hyperlipidemia and Graft Loss. Transplant Proc, 2002; 34: 2423-25.

Stephanie B, Jean PC, Georges M. Dyslipidemia following kidney transplantation: diagnosis and treatment. CurrDiab rep, 2009; 9: 305-11.

Sasa F, Gerhard K. 2012. Lipoproteins - Role in Health and Diseases. Croatia, Europe: InTech Publisher.

Shadab SM, Richard KS.Post-transplant metabolic syndrome. Int J Hepatol, 2012; 2012: 1-6

Tory R, Sachs BK, Hill JS, Wasan KM. Cyclosporine A and rapamycin induce in vitro cholesteryl ester transfer protein activity and suppress lipoprotein lipase activity in human plasma. Int J Pharm, 2008; 358:219-23.

Wallace MA. Renal transplantation. AORN J,1998;68(6):96493.

\section{How to cite this article:}

George PSG, Dhivya K. A Study on Immunosuppressant Induced Dyslipidemia and Associated Chronic Graft Rejection in Renal Transplant Recipients. J App Pharm Sci, 2016; 6 (04): 183-189. 